\title{
Emerging, crystalizing, and changing psychological contracts over time: Introducing the iPC-network model
}

Vantilborgh, Tim

Work and Organizational Psychology, Vrije Universiteit Brussel

\begin{abstract}
This chapter introduces the individual Psychological Contract (iPC) network model as an alternative approach to study psychological contracts. This model departs from the basic idea that a psychological contract forms a mental schema containing obligated inducements and contributions, which are exchanged for each other. This mental schema is captured by a dynamic network, in which the nodes represent the inducements and contributions and the ties represent the exchanges. Building on dynamic systems theory, I propose that these networks evolve over time towards attractor states, both at the level of the network structure and at the level of the nodes (i.e., breach and fulfilment attractor states). I highlight how the iPC-network model integrates recent theoretical developments in the psychological contract literature and explain how it may advance scholars understanding of exchange relationships. In particular, I illustrate how iPC-network models allow researchers to study the actual exchanges in the psychological contract over time, while acknowledging its idiosyncratic nature. This would allow for more precise predictions of psychological contract breach and fulfilment consequences and explains how content and process of the psychological contract continuously influence each other.
\end{abstract}

Keywords: Psychological contract, network model, temporal dynamics, exchange relationships, reciprocity, breach 


\section{Introduction}

Imagine Jane, a 23-year-old IO-psychologist who just graduated, starting her first job in a large multinational organization. She met with her supervisor and with some HR representatives during her application, and they described what she could expect in her new job and what they expected from her in return. Her supervisor emphasized that employees are expected to be quite flexible in terms of work hours, as big projects sometimes require staff to work late or during the weekend. Her supervisor explained that, in return, employees would be able to work from home or from a satellite office whenever they wanted to. The HR representatives explained that Jane would be able to follow various training modules on-thejob, depending on her own interests. They also mentioned that employees could participate in mindfulness classes during lunchtime, and that each employee would be assigned a mentor within the first week. They told Jane that each employee would be expected to behave professionally, both on and off the job, as corporate image was very important. Jane felt some pressure to demonstrate loyalty to the organization after this conversation.

The example above illustrates Jane's psychological contract, outlining her perception of the mutual obligations between herself and her employer (Rousseau, 1989). The psychological contract contains obligations stemming from explicit and implicit promises, originating from various sources, such as prior job experiences, promises made during recruitment, observing coworkers, HR practices, and communication from supervisors (Conway \& Briner, 2009; De Vos, Buyens, Schalk, \& Vos, 2003). In essence, the psychological contract forms a mental schema, that employees use to make sense of their daily work environment (Rousseau, 2001). They use this mental schema to monitor the progress towards attaining personally relevant goals. For example, if Jane realizes after three weeks that she is still not assigned a mentor, she may perceive a discrepancy between an obligation in her psychological contract and her day-to-day experiences, leading to perceptions of psychological contract breach (Rousseau, 1995). These perceptions of breach 
are likely to trigger an emotional response, termed feelings of violation, especially if the particular obligation is important to Jane (Morrison \& Robinson, 1997). Ultimately, these feelings of violation may translate into changes in Jane's attitudes and behaviors, such as reduced commitment, job satisfaction, job performance, and increased turnover intentions (Zhao, Wayne, Glibkowski, \& Bravo, 2007).

\section{INSERT FIGURE 1 ABOUT HERE}

The example above also illustrates that psychological contracts are mental networks of social exchange relationships, in which obligated inducements are exchanged for obligated contributions (Lambert, Edwards, \& Cable, 2003). Figure 1 visualizes Jane's psychological contract, showing that, for example, flexible work hours (a contribution by Jane) is exchanged in return for working from home (an inducement from the organization). Looking more closely at Figure 1 reveals that it is actually a network, containing nodes (i.e., the obligated inducements and contributions) that are linked by ties (i.e., arrows depicting the direction of the exchange). Yet, although psychological contracts have often been described as mental schemas (Rousseau, 2001; Sherman \& Morley, 2015), no studies actually treated them as such by using a network perspective. Instead, the content of the psychological contract is commonly studied using latent factors (e.g., transactional and relational psychological contract types) in which various inducements and contributions are aggregated and information on the exchange of inducements for contributions discarded. Likewise, studies focusing on perceptions of psychological contract breach commonly use general measures of breach in which the perceptions of breach are artificially disconnected from the actual inducements and contributions. Put simply, the literature by and large overlooks the element of exchange in psychological contracts. This is problematic, because it reduces the accuracy when predicting consequences of psychological contract breach and fulfilment. In line with the negative norm of reciprocity, the most direct response to breach of an employer 
inducement is withholding the specific employee contribution offered in exchange (Gouldner, 1960).

To address this fundamental issue in the literature, I propose a new way to operationalize and study psychological contracts in this chapter. In line with the notion that the psychological contract is a mental schema, I propose to use a dynamic network approach consisting of exchanges between inducements and contributions, as perceived by an individual employee: the individual psychological contract network (iPC-network). This approach builds on insights from Social Exchange Theory (Blau, 1964) and Dynamic Systems Theory (Vallacher, Coleman, Nowak, \& Bui-Wrzosinska, 2010; Westaby, Pfaff, \& Redding, 2014). In what follows, I will explain how the iPC-network extends current understanding of psychological contract processes, as well as demonstrates new insights that can be gained from such an approach.

\section{Traditional psychological contract research}

Psychological contracts are typically defined as an individual's perception of the mutual obligations between her- or himself and an organization (Rousseau, 1995). It is important to note that the psychological contract is considered to be idiosyncratic and subjective, meaning that every employee can perceive different obligations and that the perceptions of the employee do not necessarily align with those of the employer. Moreover, the organization is assumed to consist of various actors that represent the organization, such as a direct supervisor, HR staff, and even colleagues (Conway \& Briner, 2009; Marks, 2001). In line with this idea that there are two parties in the exchange relationship, the employee will perceive that the employer is obligated to deliver certain inducements, while the employee is obligated to deliver certain contributions in return. Therefore, some scholars argue that there are four elements that together form the psychological contract, as employees have perceptions about inducements and contributions for which they compare the extent to which 
these inducements and contributions are obligated and the extent to which they are actually delivered (Lambert, 2011).

Two major lines of research can be discerned in the psychological contract literature. The first focuses on the content of the psychological contract (i.e., what are the obligations that form the psychological contract), whereas the second focuses on psychological contract processes such as breach perceptions and feelings of violation. Research on psychological contract content often distinguishes various psychological contract types, such as transactional, relational, and ideological contracts. Transactional psychological contracts are characterized by short-term, tangible, often material inducements and contributions, such as fair pay, safe working conditions, and arriving on time (Rousseau, 1990). Relational psychological contracts involve long-term, intangible, socio-emotional inducements and contributions, such as recognition, job security, and loyalty (Rousseau, 1990). Finally, ideological psychological contracts focus on value-driven obligations, often pertaining to the mission and values of the organization (Thompson \& Bunderson, 2003), such as contributing to the stated cause, and respect for beneficiaries. Research on psychological contract content typically focuses on antecedents of psychological contract types, such as employment contract and personality traits (De Cuyper \& De Witte, 2007; Raja, Johns, \& Ntalianis, 2004), or on the benefits and downsides of certain contract types for employees and organizations, such as innovative behavior of employees (Chang, Hsu, Liou, \& Tsai, 2013).

Most studies, however, explore psychological contract processes; in particular the consequences of psychological contract breach and feelings of violation (Conway \& Briner, 2009). In line with Affective Events Theory (Weiss \& Cropanzano, 1996), perceptions of breach are believed to feelings of violation, including emotions such as anger, frustration, and resentment (Morrison \& Robinson, 1997), which in turn lead to changes in attitudes and behaviors. Meta-analyses show that feelings of violation relate negatively to organizational commitment, performance, trust, job satisfaction, and organizational citizenship behavior, 
and positively to deviant work behavior and turnover intentions (Bal, De Lange, Jansen, \& Van Der Velde, 2008; Zhao et al., 2007). One major problem in studies on psychological contract processes is that they tend to disconnect breach perceptions and feelings of violation from the actual inducements and contributions that are being exchanged in the psychological contract. Instead, they either focus on general perceptions of breach or on breach perceptions aggregated for different psychological contract types (i.e., transactional, relational, and ideological psychological contract breach; Montes \& Irving, 2008; Vantilborgh et al., 2014). By doing so, they disregard that reactions to breach perceptions depend on the particular inducement breached (Lambert, 2011) and on the extent to which employees actually delivered contributions in return (Morrison \& Robinson, 1997). As I will show further on, the iPC-network approach solves these issues by taking the exchange of specific inducements and contributions into account.

It is worth noting that researchers have started to emphasize the dynamic nature of the psychological contract in recent years (Conway \& Briner, 2002; Griep, Vantilborgh, Baillien, \& Pepermans, 2016; Tomprou, Rousseau, \& Hansen, 2015; Vantilborgh, Bidee, Pepermans, Griep, \& Hofmans, 2016). Psychological Contract Theory 2.0 (for a summary see Hansen \& Griep, 2016; see also Chapter X by Tomprou and Bankins in this book) states that psychological contracts go through distinct phases. When employees start a new job, the psychological contract takes shape (formation phase). Once the psychological contract stabilizes, employees enter a maintenance phase, in which they use their psychological contract to monitor the extent to which their goals are met. This monitoring happens almost automatically with low cognitive effort. If a discrepancy is perceived between what is obligated and what is actually delivered, employees enter a disruption phase. In case of a positive discrepancy (i.e., over-fulfilment: receiving more than obligated), employees attempt to restore balance in their psychological contract by renegotiating their contract - a process characterized by positive affect — while in case of negative discrepancies (i.e., under- 
fulfilment: receiving less than obligated) they will integrate the new information in a repaired contract - a process characterized by negative affect. A major contribution of this theory is the notion that psychological contracts evolve dynamically over time; obligated inducements and contributions may enter and disappear from a contract due to formation or disruption processes.

Another important model that emphasizes the dynamic nature of the psychological contract was proposed by Schalk and Roe (2007). Their model introduces a dynamic threshold to perceive psychological contract breach. They argue that not every discrepancy between obligated and delivered inducements will be interpreted as a breach; only when the discrepancy is large enough to cross a threshold will employees consider their psychological contract to be breached. This threshold is believed to differ between individuals-i.e., some employees may be more prone to interpret a deviation from an obligation as a breach — but also within individuals over time-e.g., due to repeated breaches, the threshold may decrease resulting in a higher likelihood to perceive new breaches.

Finally, the post-violation model explains that certain trajectories can be distinguished in the aftermath of psychological contract breach and the ensuing feelings of violation (Tomprou et al., 2015; see also Chapter X by Tomprou and Bankins in this book). In particular, this model distinguishes four post-violation states that can emerge: thriving (the psychological contract is improved compared to pre-breach state), reactivation (the psychological contract is restored to pre-breach state), impairment (the psychological contract is worse compared to pre-breach state), and dissolution (the psychological contract deteriorates significantly compared to the pre-breach state). As I will explain below, these three dynamic psychological contract theories are integrated in the iPC-network model.

\section{The iPC-network model}

The iPC-network model departs from the idea that an individual's psychological contract can be operationalized as a network, consisting of nodes (obligated inducements or 
obligated contributions) and ties linking different-sort nodes. Fundamentally, this model is considered to be dynamic, meaning that the nodes and ties in the network may change over time. This mirrors the changes that stem from different psychological contract phases (Hansen \& Griep, 2016) or from reactions to psychological contract breach and feelings of violation (Tomprou et al., 2015). To better understand these changes, we draw from dynamic systems theory and introduce the concept of attractor states (Westaby et al., 2014). An attractor forms a subset of states of processes towards which a system converges over time (Vallacher et al., 2010). In view of the iPC-network model, we propose that attractors exist at two levels: the structure of the network (i.e., the nodes and the ties) and the state of the nodes themselves (i.e., fulfilled or breached inducements and contributions).

At the level of the network structure, the content (i.e., the inducements and contributions) and the exchanges between them are proposed to converge to an attractor, representing a balance between the goals of the employee and the employer. For example, an employee who values socio-emotional inducements, such as recognition and job security, is likely to form a psychological contract in which these inducements play a central role. This is because people seek out, construe, and through their own behaviours shape psychological contracts (Raja et al., 2004). At the level of the nodes, I propose that inducements and contributions can take one of three states: under-fulfilled (i.e., receiving less than obligated), over-fulfilled (i.e., receiving more than obligated), or fulfilled (i.e., receiving exactly what was obligated). Given that people seek out information that confirms their prior beliefs (Fiske \& Taylor, 1991), the state of a node is considered to be — to a certain extent—resistant to change. For example, a node that is fulfilled at time $\mathrm{T}$ and has a strong attractor to being fulfilled, is less likely to be interpreted as breached at a later point in time. Hence, this attractor at the level of nodes corresponds with the idea of a threshold to perceive a psychological contract breach (Griep et al., 2016; Hofmans, 2017; Schalk \& Roe, 2007): a strong attractor implies a high threshold, meaning that it is more difficult for a node to switch 
from one state (e.g., under-fulfilled) to another state (e.g., fulfilled). However, the iPCnetwork model assumes that the attractors for the three possible states can differ from each other, meaning that three distinct thresholds exist. Figure 2 visualizes these two attractors. In line with Dynamic Systems Theory, each attractor is represented by a basin with a certain width and depth (Vallacher et al., 2010). The width of the basin represents the range of states that would evolve towards the attractor. In view of psychological contract breach, this would represent the range of discrepancies between obligated and delivered inducements that would be interpreted as either an under- or over-fulfilment, or a fulfilment. The depth of the basin represents the strength of the attractor or its resistance to change. In Figure 2, the attractor of fulfilment has a larger depth, meaning that it is more resistant to change, compared to the attractor of fulfilment. This implies that more information would be required for an employee to decide that this particular inducement is not fulfilled, pulling that inducement out of the state of fulfilment and into the state of under-fulfilment.

\section{INSERT FIGURE 2 ABOUT HERE}

Drawing from Psychological Contract Theory 2.0, I propose that the iPC-network distinguishes various phases in psychological contract development. During the formation phase, the iPC-network is formed, as the employee receives information from various actors representing the organization and gains first-hand experience (for a summary see Hansen \& Griep, 2016; see also Chapter X by Tomprou and Bankins in this book). The iPC-network is quite volatile during this phase and undergoes frequent changes: nodes and ties can be added or removed. For example, due to pre-employment experiences an employee may perceive certain obligated inducements in his/her iPC-network, but soon realize that these obligated inducements are not realistic in his/her current occupation and hence abandons them (De Vos et al., 2003). Or alternatively, the tie between an inducement and a contribution may start out weak because the employee is uncertain whether the employer actually expects him or her to reciprocate a certain inducement with that specific contribution (e.g., am I expected to 
respond to emails during the weekend in return for the ability to work from home?). Over time, this tie may strengthen because a pattern of interaction is established that reinforces the exchange between the inducement and contribution (e.g., each time that a supervisor mentions that the employee can work from home, she also stresses that she expect the employee to reply to emails as swiftly as possible, even during the weekend). Gradually, the iPC-network is expected to gravitate towards an attractor state that balances the needs and goals of the employee (i.e., flexible work arrangement) and the employer (i.e., being reachable at all times). This implies that undesired or unrealistic inducements and contributions are gradually removed from the iPC-network, while ties that reflect a stable pattern of mutual interactions remain. Once the iPC-network enters this attractor state, it reaches a point of equilibrium, meaning that it becomes more resistant to change. In terms of Psychological Contract Theory 2.0, the psychological contract moves from the formation phase to the maintenance phase.

During the maintenance phase, the iPC-network is expected to be stable. Employees use the iPC-network as a mental scheme to monitor the attainment of personally valued goals (i.e., important inducements). This monitoring requires little effort, and occurs almost automatically (Hansen \& Griep, 2016). As long as all the nodes are in a state of fulfilment, the iPC-network operates largely implicitly in the background of employees' minds (Conway \& Briner, 2009). However, once an employee perceives a discrepancy that changes the state of one or more nodes from fulfilment to under- or over-fulfilment, a number of reactions are triggered in the iPC-network. In particular, I propose that the state of a node can have an impact on the state of connected nodes, an impact on ties with connected nodes, and an impact on the attractors of the node.

Impact on state of connected nodes. In line with the negative norm of reciprocity (Chen, Chen, \& Portnoy, 2009), a breach in the iPC-network is likely to trigger a change in the state of connected nodes. When an obligated inducement is perceived to be under- 
fulfilled, the employee can respond by withholding the contributions that are obligated in return (Rousseau, 1995). Vice versa, when an obligated contribution is under-fulfilled, the employer can also decide to no longer deliver the inducements that are owed in exchange ${ }^{1}$. In the iPC-network model, the ties indicate which specific contributions are exchanged for which specific inducements and vice versa. Hence, when an inducement enters the state of under-fulfilment in an iPC-network at time $\mathrm{T}$, there is a likelihood that the contributions that are tied to it will also enter a state of under-fulfilment at time $\mathrm{T}+1$. This likelihood depends on two factors: 1) the strength of the tie, and 2) the attractor strength of the contribution. If the tie has a weak strength, there is uncertainty surrounding the exchange, reducing the likelihood that the employee will decide to withhold that particular contribution. If the attractor of the (over-)fulfilment state of the contribution is strong, it will be difficult to pull the contribution out of this state into a state of under-fulfilment, again reducing the likelihood that a particular contribution will be withheld. Figure 3 visualizes this process, and illustrates that there is a higher likelihood that contribution A, relative to contribution $\mathrm{B}$, will be withheld at time $\mathrm{T}+1$ because there is a stronger tie between the under-fulfilled inducement and contribution A and a weaker attractor strength for the fulfilment state of contribution A. Hence, a major advantage of the iPC-network model is that it can predict the most likely, specific reaction of employees to perceptions of breach. Moreover, an implication of this is that the iPC-network can model the "epidemic" spread of breach across the network, mimicking escalation of conflict (Andersson \& Pearson, 1999; Griep \& Vantilborgh, 2018).

\section{INSERT FIGURE 3 ABOUT HERE}

Impact on ties with connected nodes. When a node enters an under-fulfilled state, I propose that there will also be an effect on the strength of the ties with connected nodes. In particular, the longer a node remains in the under-fulfilled state, the weaker the ties with

\footnotetext{
${ }^{1}$ I propose that over-fulfilment can trigger positive behaviours reinforcing the exchange, albeit less strong than under-fulfilment.
} 
connected nodes will become. This represents the notion that breach creates uncertainty on exchanges. Ultimately, ties may become so weak that they dissolve, potentially leading to a situation in which all the ties between the under-fulfilled node and the connected nodes disappear. In this situation, the node would be removed from the iPC-network, suggesting that a particular obligation no longer forms a part of the psychological contract. When nodes are in a state of fulfilment or over-fulfillment, I expect the reverse effect to hold, meaning that ties strengthen as long as obligations are (over-)fulfilled due to a reduction in uncertainty surrounding the exchange. Over time, changes in the strength of ties may lead to different network structures or attractor states. For example, an under-fulfilment may lead to certain inducements and contributions disappearing from the iPC-network before it resettles in a new attractor state representing an impaired psychological contract (Tomprou et al., 2015).

Impact on attractors of the node. Finally, the state of a node - under-fulfilled, overfulfilled or fulfilled - has an impact on the strength of the attractor of that same node. When an inducement or contribution is repeatedly (under-/over-)fulfilled, the basin of the attractor deepens, thus increasing the strength of that attractor. Put differently, repeated breaches or fulfilments will entrench this state, making it more resistant to change. For example, an inducement that is repeatedly fulfilled will require stronger evidence, such as a larger discrepancy or a large number of repeated negative discrepancies, before an employee will consider a discrepancy as a breach. The idea that breach and fulfilment influences the strength of attractors implies that the history of breaches and fulfilments in the exchange relationship is imprinted in these attractors. An exchange relationship characterized by a long history of repeated under-fulfilments will have strong attractors for under-fulfilment states, while an exchange relationship with mostly fulfilled obligations will have strong attractors for fulfilment states.

\section{Network characteristics}


Given that the iPC-network model operationalizes psychological contracts as dynamic networks, a number of network characteristics can be computed that offer valuable information for psychological contract researchers. While it is beyond the scope of this chapter to discuss all possible network characteristics, I will highlight three said characteristics that have a clear relevance for psychological contracts: 1) the degree of nodes, 2) reciprocity, and 3) community structures.

Degree. The degree $k_{i}$ represents the number of ties a node has and is calculated by $k_{i}=\sum a_{i j}$, with $a_{i j}$ denoting the ties going from node $i$ to a connected node $j$ (Boccaletti, Latora, Moreno, Chavez, \& Hwang, 2006). Because the iPC-network is a directed networki.e., ties either go from an inducement to a contribution or from a contribution to an inducement - two types of degree can be calculated: 1) the in-degree, and 2) the out-degree. The in-degree is the total number of incoming ties, representing the amount of contributions/inducements for which the inducement/contribution is obligated in return. The out-degree is the total number of outgoing ties, representing the amount of contributions/inducements that are obligated in return for the inducement/contribution. The degree of a node is often used as a measure of centrality in networks; the more ties a node has, the more central—and hence, the more important—a node is in the network (Opsahl, Agneessens, \& Skvoretz, 2010). As a result, the degree of a node could serve as a measure of importance of a certain obligation in the psychological contract. This could then be related to factors that explain variation in importance, such as career stage, personality traits, or values (Cohen, 2011; Low, Bordia, \& Bordia, 2016; Raja et al., 2004). Alternatively, it could be used as a moderator to gain a better understanding of differential reactions to psychological contract breach, as reactions tend to be stronger when the breached obligation is considered important (Morrison \& Robinson, 1997).

In addition, the degree distribution $P(k)$ can be used to assess the robustness of an iPC-network (Boccaletti et al., 2006). A network is considered to be robust when randomly 
removing a node does fundamentally change the properties (e.g., the reciprocity or community structure) of the network. Based on $P(k)$, one can look for the presence of giant components in the network ${ }^{2}$, which are indicative of robustness. Related to the iPC-network, the presence of a giant component would suggest that the psychological contract is robust. Put differently, removing a node or a tie from the iPC-network (e.g., due to an underfulfilment) would not fundamentally change the properties of the psychological contract, meaning that the removal would not disrupt the exchange relationship.

Reciprocity. A network characteristic with particular relevance to psychological contract researchers is reciprocity, commonly operationalized as the percentage of possible ties that are symmetric. In the example at the outset of this chapter (see Figure 1), Jane's iPCnetwork contains 3 symmetric sets of ties, namely between 1) working from home or satellite office and working flexible hours, 2) following training modules and being loyal, and 3) receiving help from a mentor and being loyal. Given that there are 12 possible ties between all the different inducements and contributions, the reciprocity in this network is .25 or $25 \%$. Moreover, 4 of the $12(33 \%)$ possible ties pertain to contributions owed by the employee in return for employer inducements, and there are no unidirectional ties pertaining to inducements owed by the employer in return for employee contributions. The remaining 5 of the 12 possible ties are not present in the iPC-network. Combined, this information suggests that the iPC-network is characterized by a situation of employee over-obligation (De Cuyper, Rigotti, Witte, \& Mohr, 2008; Vantilborgh et al., 2013), aligning with the notion of a generalized, positive norm of reciprocity (Wu et al., 2006). A more fine-grained understanding of reciprocity could be obtained if the ties are assigned weights, capturing the strength of the exchange (see Squartini, Picciolo, Ruzzenenti, \& Garlaschelli, 2013).

Community structures. A community structure is a sub-graph of a network with highly connected or cohesive nodes (Boccaletti et al., 2006). The most extreme case of this

\footnotetext{
${ }^{2}$ A giant component is present when $\sum_{k} k(k-2) P(k)>2$ (see Boccaletti et al., 2006).
} 
are cliques, referring to a subset of three or more nodes that all have ties to each other, but not to any other nodes in the network. A less extreme situation pertains to the situation in which a subgroup of nodes is dense-i.e., has a high number of ties between them-while the ties with other nodes are sparse. Hence, a community $G^{\prime}$ can be said to exist if the sum of all degrees within $G^{\prime}$ is larger than the sum of all degrees toward the rest of the graph. For example, in Figure 1 the inducement "work from home or satellite office" and the contribution "be willing to work flexible hours" would form a community structure because the sum of ties in this community is 2 whereas the sum of ties going to nodes outside of the community is 1 . Practically speaking, community structures can help to find clusters of obligations in an iPC-network. These clusters could indicate the presence of inducements and contributions that share a common characteristic, such as a shared actor (i.e., the direct supervisor in the example). In addition, clusters could help to assess if transactional, relational, and ideological inducements and contributions tend to form subgroups or not. Theoretically, clusters within the psychological contract would further our understanding of multiple foci in the contract (Marks, 2001) and would help to further develop psychological contract typologies.

\section{Studying iPC-networks in practice}

Using a network approach to psychological contract research not only means that researchers need to use different analytical procedures, but also that they need to collect data in a different way. Traditional measures of psychological contract content and processes will not suffice to reconstruct iPC-networks (Freese \& Schalk, 2008). Instead, I propose that researchers use specific qualitative or quantitative measurement instruments, or rely on computational models to study iPC-networks. I will now briefly discuss each of these options in more detail.

Qualitative approach. A potentially rich way to obtain information on iPC-networks is to ask people to draw the mental schema during an interview. The interviewee could be 
asked to first list all inducements and contributions that are considered relevant in his or her current exchange relationship. Subsequently, the interviewee would be asked to draw arrows between the inducements and contributions, indicating all the perceived exchanges. This would result in an unweighted matrix (i.e., a matrix in which 0 and 1 represent the absence or presence of a tie respectively) that can then be used to calculate a network model for that interviewee using statistical programs (e.g., R packages such as qgraph (Epskamp, Kramer, Waldorp, Schmittmann, \& Borsboom, 2012) and igraph (Csardi \& Nepusz, 2006)). The advantage of this approach is that the interviewer can potentially obtain rich data and that the interviewee can construct his or her mental schema in a more organic manner, leaving room for making changes to the network throughout the entire process. Although cumbersome, it would be possible to use a longitudinal design, with each interviewee constructing their iPCnetwork at different points in time to investigate changes in the structure of their psychological contract. In addition, the interviewee could be asked to rate the strength of ties and to indicate the current state of nodes (under-fulfilled, over-fulfilled, or fulfilled).

\section{INSERT FIGURE 4 ABOUT HERE}

Quantitative approach. An alternative approach is to use surveys to obtain quantitative data. Respondents would first be offered a list of potential inducements and contributions, and select those that are relevant to their current exchange relationship. Next, for each inducement, respondents indicate to what extent each contribution is obligated in return for each inducement. Next, this process is reversed and respondents would indicate, for each contribution, to what extent each inducement is obligated in return. This would again result in a weighted matrix (i.e., a matrix in which 0 represents the absence of a tie and nonzero values represent the strength of a tie) that can be used to compute the iPC-network for each respondent. Respondents could also be asked to indicate which inducements and contributions are under-fulfilled, over-fulfilled, or fulfilled. While this approach would immediately yield a dataset that can be used as an input for network analysis (e.g., with 
qgraph or igraph $\mathrm{R}$ packages), the downside is that the length of the survey increases dramatically as the number of inducements and contributions selected by the respondent increases. For example, 4 questions with 2 response options are required when focusing on 2 inducements and 2 contributions, whereas 8 questions with 4 response options would be necessary when using 4 inducements and 4 contributions. It is also recommended that respondents be allowed to add additional inducements or contributions to the survey (e.g., using open questions) to ensure that the unique elements in each respondents' iPC-network are captured.

Computational models. A promising approach is the use of computational models (Weinhardt \& Vancouver, 2012; see also Chapter X by Weinhardt, Griep, \& Sosnowska in this book). In such models, an iPC-network is simulated, while offering the possibility to vary certain aspects of the network, such as the number of nodes, the strength of ties, the state of nodes, or the attractor strength of node states. In these virtual experiments, the researcher can set the starting values (e.g., the nodes, the strength of ties, the strength of attractor states, etcetera) of the iPC-network model and subsequently test how the network changes over time. Differential equations can be used to model how elements in the network (e.g., the state of a node) would change as a function of other network elements (e.g., the state of connected nodes, the strength of ties, and the strength of the attractor). The results of these computational models are especially useful to develop new theoretical insights, which can then be empirically tested using the qualitative or quantitative approaches outlined above.

\section{Discussion}

The goal of this chapter was to introduce readers to a new approach to studying psychological contracts. I propose that the iPC-networks model—which treats an individual's psychological contract as a dynamic network-forms a novel method that strongly aligns with the basic premises of Psychological Contract Theory (Rousseau, 1989; 2001) in several important ways. First, it acknowledges that psychological contracts involve two parties 
(Tekleab \& Taylor, 2003), by focusing on both employer (i.e., inducements) and employee (i.e., contributions) obligations. While employee contributions have been the topic of a number of studies (e.g., Lambert, 2011; Vantilborgh et al., 2013), most studies to date focused exclusively on employer inducements. The iPC-network model brings the exchange of inducements in return for contributions to the forefront, thus re-establishing the importance of social exchanges in psychological contracts. Second, the iPC-networks model simultaneously addresses the content and the processes of psychological contracts. These two elements were often artificially disconnected in previous work; at best, researchers relied on latent factors such as transactional and relational psychological contract types, which implies a loss of information by aggregating the various specific inducements and contributions into these latent factors. In contrast, the iPC-network model proposes that content and process are inherently intertwined, thus following the idea from network theory that structure and process of a network continuously influence each other (Boccaletti et al., 2006). Third, the iPCnetwork model acknowledges that psychological contracts are idiosyncratic, by allowing each individual's iPC-network to be composed of different, unique inducements, contributions, and ties connecting both.

I believe that studying psychological contracts as dynamic networks opens up various interesting new avenues for research, that have the potential to profoundly advance our understanding of psychological contracts. For example, using computational tools to model the spread of breach perceptions throughout an iPC-network would be valuable in creating new theoretical insights on how psychological contracts dynamically form, evolve, and dissolve over time (for an overview see Hansen \& Griep, 2016; see also Chapter X by Weinhardt, Griep, \& Sosnowska in this book). Such theoretical insights are direly needed because researchers aiming to conduct empirical studies that unravel temporal dynamics in psychological contracts have lamented the lack of theoretical guidelines (for a critique see Griep \& Vantilborgh, 2018). Moreover, the introduction of a dynamic systems approach and 
the notion of attractor states can help to explain previously inconsistent findings, such as the absence of employee reactions in a situation of psychological contract breach. Finally, it is worth pointing out that the iPC-network model is able to accommodate various recent theoretical advances in psychological contract research-i.e., the Dynamic Psychological Contract Model (Schalk \& Roe, 2007), Psychological Contract Theory 2.0 (for an overview see Hansen \& Griep, 2016), and the Post-Violation Model (Tomprou et al., 2015)—into its model. It is thus able to explain both short-term (i.e., post-breach changes) and long-term changes (i.e., formation, maintenance, disruption phases) to the psychological contract.

\section{Limitations and recommendations for future research}

Although the iPC-network model addresses a number of shortcomings in traditional psychological contract research, it also introduces a number of challenges for researchers who aim to implement this approach. First, using surveys to measure the iPC-network may require respondents to fill out relatively long questionnaires. As mentioned above, the length of the survey increases exponentially as the number of relevant inducements and contributions in the respondents' psychological contract goes up. This may become problematic when using surveys in a longitudinal study because the length of the surveys may result in respondent fatigue and increased dropout. Researchers could therefore opt to use other approaches (e.g., qualitative approach or computational modelling) or they could choose to focus on a limited set of inducements and contributions. The downside of the latter is that the respondents' iPC-networks will be incomplete, introducing the issue of omitted variables.

Second, a major advantage of the iPC-network model is that it brings the dynamic nature of the psychological contract to the forefront. However, this introduces the issue of selecting the appropriate time-frame to measure changes in the nodes and ties of iPCnetworks. To date, there are no theoretical guidelines on optimal time lags in psychological contract research (Vantilborgh et al., 2016). Exploratory research is needed to establish 
guidelines on optimal time lags (Dormann \& Griffin, 2015), while taking into account that optimal time lags may depend on contextual factors, such as the phase (e.g., formation versus maintenance) of the psychological contract.

Finally, it may be computationally burdensome to estimate iPC-network models in their entirety and collecting empirical data on all iPC-network model elements simultaneously may prove difficult. However, it is important to emphasize that the iPCnetwork model functions as a theoretical backdrop, from which specific hypotheses can be selected and tested in empirical studies. For example, experiments could be designed in which a psychological contract is established with participants, followed by a breach of a specific inducement. This could then be used to test the extent to which this breach influences other elements (ties and nodes) in each participants' iPC-network, hence testing hypotheses pertaining to the impact of breached nodes on other nodes and tie strength.

\section{Conclusion}

In this chapter, I introduce the iPC-network model which models the psychological contract as a dynamic network consisting of nodes representing the inducements and contributions in the contract and ties representing the exchanges between these obligations. The iPC-network model thus puts the exchange between two parties front-and-centre, while acknowledging that process and content of the psychological contract continuously influence each other and that the psychological contract is inherently idiosyncratic. I illustrate how these iPC-network models can be studied using qualitative, quantitative, and computational modelling techniques. 


\section{References}

Andersson, L. M., \& Pearson, C. M. (1999). Effect of Tit for Tat? the Spiraling in the Workplace Incivility. Academy of Management Review, 24(3), 452-471. doi: $10.2307 / 259136$

Bal, P. M., De Lange, A. H., Jansen, P. G. W., \& Van Der Velde, M. E. G. (2008). Psychological contract breach and job attitudes: A meta-analysis of age as a moderator. Journal of Vocational Behavior, 72(1), 143-158. doi: 10.1016/j.jvb.2007.10.005

Blau, P. (1964). Exchange and power in social life. New York, NY: Wiley.

Boccaletti, S., Latora, V., Moreno, Y., Chavez, M., \& Hwang, D. (2006). Complex networks: Structure and dynamics. Physics Reports, 424(4-5), 175-308. doi: 10.1016/j.physrep.2005.10.009

Chang, H. T., Hsu, H. M., Liou, J. W., \& Tsai, C. T. (2013). Psychological contracts and innovative behavior: A moderated path analysis of work engagement and job resources. Journal of Applied Social Psychology, 43(10), 2120-2135. doi: 10.1111/jasp.12165

Chen, Y. R., Chen, X. P., \& Portnoy, R. (2009). To whom do positive norm and negative norm of reciprocity apply? Effects of inequitable offer, relationship, and relational-self orientation. Journal of Experimental Social Psychology, 45(1), 24-34. doi: 10.1016/j.jesp.2008.07.024

Cohen, A. (2011). Values and psychological contracts in their relationship to commitment in the workplace. Career Development International, 16(7), 646-667. doi: $10.1108 / 13620431111187272$

Conway, N., \& Briner, R. B. (2002). A daily diary study of affective responses to psychological contract breach and exceeded promises. Journal of Organizational Behavior, 23(3), 287-302. doi: 10.1002/job.139

Conway, N., \& Briner, R. B. (2009). Fifty years of psychological contract research: What do we know and what are the main challenges? International Review of Industrial and 
Organizational Psychology, 21, 71-131. doi: 10.1002/9780470745267.ch3

Csardi, G., \& Nepusz, T. (2006). The igraph software package for complex network research. InterJournal, Complex Systems, 1695(5), 1-9.

De Cuyper, N., \& De Witte, H. (2007). Job insecurity in temporary versus permanent workers: Associations with attitudes, well-being, and behaviour. Work \& Stress, 21(1), 65-84. doi: 10.1080/02678370701229050

De Cuyper, N., Rigotti, T., Witte, H. De, \& Mohr, G. (2008). Balancing psychological contracts: Validation of a typology. The International Journal of Human Resource Management, 19(4), 543-561. doi: 10.1080/09585190801953590

De Vos, A., Buyens, D., Schalk, R., \& Vos, A. De. (2003). Psychological contract development during organizational socialization: adaptation to reality and the role of reciprocity. Journal of Organizational Behavior, 24(5), 537-559. doi: 10.1002/job.205

Dormann, C., \& Griffin, M. A. (2015). Optimal time lags in panel studies. Psychological Methods, 20(4), 489-505. doi: 10.1037/met0000041

Epskamp, S., Cramer, A. O. J., Waldorp, L. J., Schmittmann, V. D., \& Borsboom, D. (2012). qgraph: Network visualizations of relationships in psychometric data. Journal of Statistical Software, 48(4), 1-18.

Fiske, S., \& Taylor, S. (1991). Social cognition (2nd editio). New York: McGraw-Hill. Freese, C., \& Schalk, R. (2008). How to measure the psychological contract? A critical criteria-based review of measures. South African Journal of Psychology, 38(2), 269286.

Griep, Y., \& Vantilborgh, T. (2018). Reciprocal effects of psychological contract breach on counterproductive and organizational citizenship behaviors: The role of time. Journal of Vocational Behavior, 104. doi: 10.1016/j.jvb.2017.10.013

Griep, Y., Vantilborgh, T., Baillien, E., \& Pepermans, R. (2016). The mitigating role of leader-member exchange when perceiving psychological contract violation: a diary 
survey study among volunteers. European Journal of Work and Organizational Psychology, (May 2015), 1-18. doi: 10.1080/1359432X.2015.1046048

Gouldner, A. W. (1960). The norm of reciprocity: A preliminary statement. American Sociological Review, 25(2), 161-178. doi: 10.2307/209262

Hansen, S. D., \& Griep, Y. (2016). Psychological contracts. In J. P. Meyer (Ed.), Handbook of employee commitment (pp. 119-134). Edward Elger Publishing. doi: $10.4337 / 9781784711740$

Hofmans, J. (2017). Modeling Psychological Contract Violation using Dual Regime Models: An Event-based Approach. Frontiers in Psychology, 8(November), 1-11. doi: 10.3389/fpsyg.2017.01948

Lambert, L. (2011). Promised and delivered inducements and contributions: An integrated view of psychological contract appraisal. Journal of Applied Psychology, 96(4), 695712. doi: $10.1037 / \mathrm{a} 0021692$

Lambert, L., Edwards, J., \& Cable, D. M. (2003). Breach and fulfillment of the psychological contract: A comparison of traditional and expanded views. Personnel Psychology, 56(4), 895-934. doi: 10.1111/j.1744-6570.2003.tb00244.x

Low, C. H., Bordia, P., \& Bordia, S. (2016). What do employees want and why? An exploration of employees' preferred psychological contract elements across career stages. Human Relations, 1-25. doi: 10.1177/0018726715616468

Marks, A. (2001). Developing a multiple foci conceptualization of the psychological contract. Employee Relations, 23(5), 454-467. doi: 10.1108/eum0000000005897

Montes, S. D., \& Irving, P. G. (2008). Disentangling the effects of promised and delivered inducements: Relational and transactional contract elements and the mediating role of trust. Journal of Applied Psychology, 93(6), 1367-1381. doi: 10.1037/a0012851

Morrison, E., \& Robinson, S. (1997). When employees feel betrayed: A model of how psychological contract violation develops. Academy of Management Review, 22(1), 
226-256. doi: 10.5465/amr.1997.9707180265

Opsahl, T., Agneessens, F., \& Skvoretz, J. (2010). Node centrality in weighted networks: Generalizing degree and shortest paths. Social Networks, 32(3), 245-251. doi: 10.1016/j.socnet.2010.03.006

Raja, U., Johns, G., \& Ntalianis, F. (2004). The impact of personality on psychological contracts. Academy of Management Journal, 47(3), 350-367. doi: 10.2307/20159586

Rousseau, D. (1989). Psychological and implied contracts in organizations. Employee Responsibilities and Rights Journal, 2(2), 121-139. doi: 10.1007/BF01384942

Rousseau, D. (1990). New hire perceptions of their own and their employer's obligations: A study of psychological contracts. Journal of Organizational Behavior, 11(5), 389-400. doi: $10.1002 /$ job.4030110506

Rousseau, D. (1995). Psychological contracts in organizations: Understanding written and unwritten agreements. Thousand Oaks: SAGE Publications.

Rousseau, D. (2001). Schema, promise and mutuality: The building blocks of the psychological contract. Journal of Occupational and Organizational Psychology, 74(4), 511-541. doi: 10.1348/096317901167505

Schalk, R., \& Roe, R. E. (2007). Towards a dynamic model of the psychological contract. Journal for the Theory of Social Behaviour, 37(2), 167-182. doi: 10.1111/j.14685914.2007.00330.x

Sherman, U. P., \& Morley, M. J. (2015). On the Formation of the Psychological Contract: A Schema Theory Perspective. Group \& Organization Management, 40(2), 160-192. doi: $10.1177 / 1059601115574944$

Squartini, T., Picciolo, F., Ruzzenenti, F., \& Garlaschelli, D. (2013). Reciprocity of weighted networks. Nature, 3, 1-9. doi: 10.1038/srep02729

Tekleab, A. G., \& Taylor, M. S. (2003). Aren't there two parties in an employment relationship? Antecedents and consequences of organization-employee agreement on 
contract obligations and violations. Journal of Organizational Behavior, 24(5), 585608. doi: 10.1002/job.204

Thompson, J. A., \& Bunderson, J. S. (2003). Violations of principle: Ideological currency in the psychological contract. Academy of Management Review, 28(4), 571-586. doi: $10.2307 / 30040748$

Tomprou, M., Rousseau, D. M., \& Hansen, S. D. (2015). The psychological contracts of violation victims: A post-violation model. Journal of Organizational Behavior, 30(July), 839-862. doi: 10.1002/job

Vallacher, R. R., Coleman, P. T., Nowak, A., \& Bui-Wrzosinska, L. (2010). Rethinking intractable conflict: The perspective of dynamical systems. American Psychologist, 65(4), 262-278. doi: 10.1037/a0019290

Vantilborgh, T., Bidee, J., Pepermans, R., Griep, Y., \& Hofmans, J. (2016). Antecedents of Psychological Contract Breach: The Role of Job Demands, Job Resources, and Affect. Plos One, 11(5), e0154696. doi: 10.1371/journal.pone.0154696

Vantilborgh, T., Bidee, J., Pepermans, R., Willems, J., Huybrechts, G., \& Jegers, M. (2013). From "getting" to "giving": Exploring age-related differences in perceptions of and reactions to psychological contract balance. European Journal of Work and Organizational Psychology, 22(3), 293-305. doi: 10.1080/1359432X.2012.721354

Vantilborgh, T., Bidee, J., Pepermans, R., Willems, J., Huybrechts, G., \& Jegers, M. (2014). Effects of ideological and relational psychological contract breach and fulfilment on volunteers' work effort. European Journal of Work and Organizational Psychology, 23(2), 217-230. doi: 10.1080/1359432X.2012.740170

Weinhardt, J. M., \& Vancouver, J. B. (2012). Computational models and organizational psychology: Opportunities abound. Organizational Psychology Review, 2(4), 267-292. doi: $10.1177 / 2041386612450455$

Weiss, H. M., \& Cropanzano, R. (1996). Affective events theory: A theoretical discussion of 
the structure, causes and consequences of affective experiences at work. In M. Barry \& L. L. Cummings (Eds.), Research in organizational behavior: An annual series of analytical essays and critical reviews (pp. 1-74). Elsevier Science.

Westaby, J. D., Pfaff, D. L., \& Redding, N. (2014). Psychology and social networks: A dynamic network theory perspective. American Psychologist, 69(3), 269-284. doi: $10.1037 / \mathrm{a} 0036106$

Wu, J. B., Hom, P. W., Tetrick, L. E., Shore, L. M., Jia, L., Li, C., \& Song, L. J. (2006). The Norm of Reciprocity: Scale Development and Validation in the Chinese Context. Management and Organization Review, 2(3), 377-402. doi: 10.1111/j.17408784.2006.00047.x

Zhao, H., Wayne, S. J., Glibkowski, B. C., \& Bravo, J. (2007). The impact of psychological contract breach on work-related outcomes: A meta-analysis. Personnel Psychology, 60(3), 647-680. doi: 10.1111/j.1744-6570.2007.00087.x 


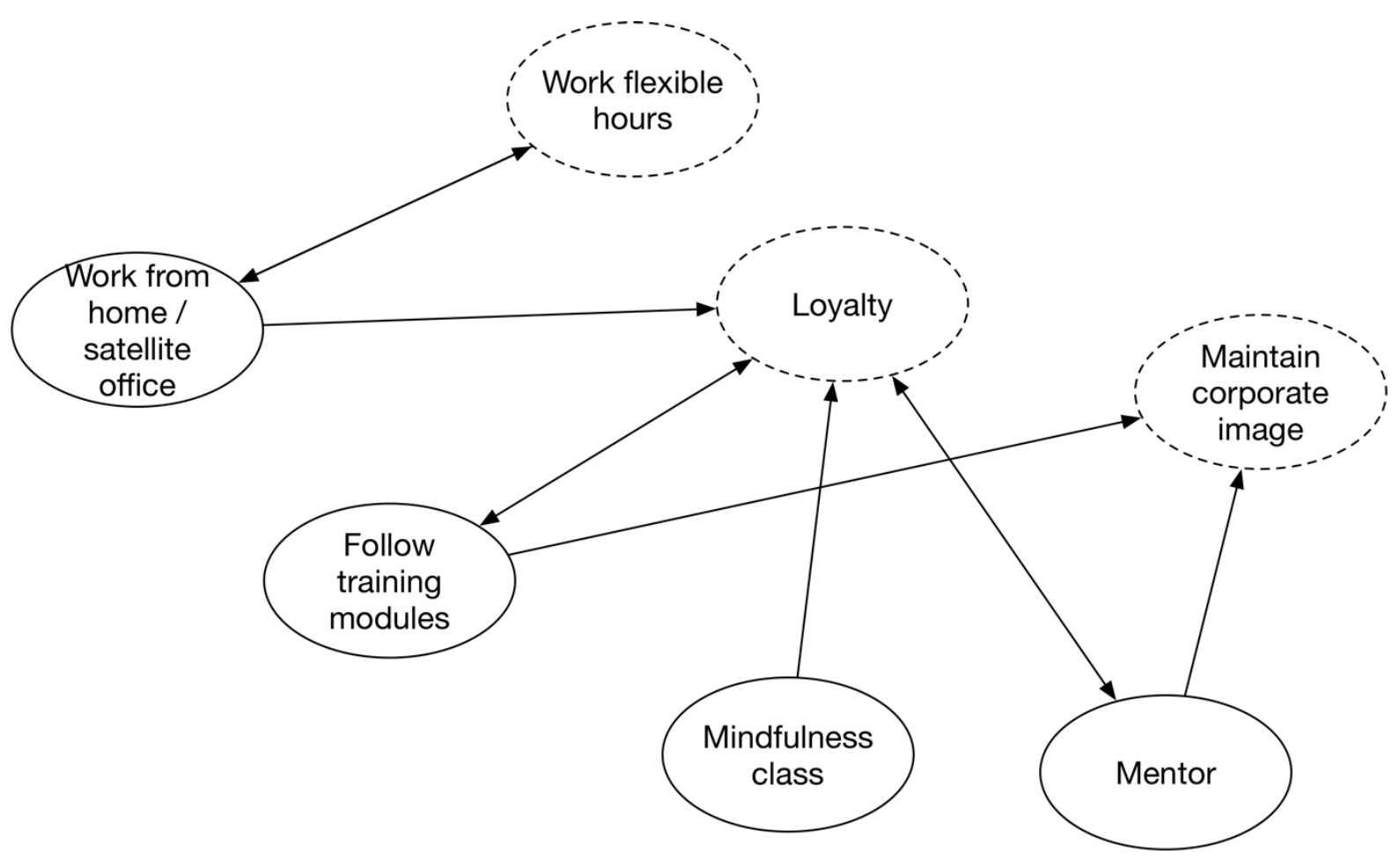

Figure 1. Example iPC-network (circles with dashed edge represent employee contributions, circles with full edge represent employer inducements). 


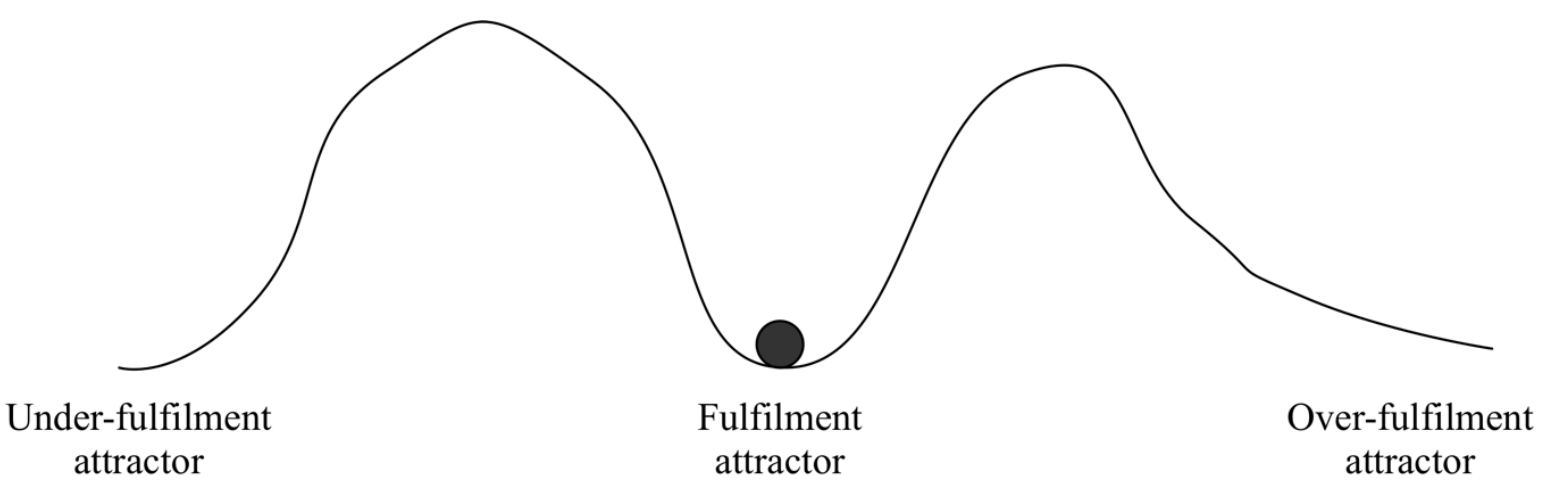

Figure 2. Visualization of attractors (under-fulfilled, over-fulfilled, or fulfilled) at the level of the nodes (i.e., inducements and obligations). The filled circle represents the state of a node at a discrete point in time. 


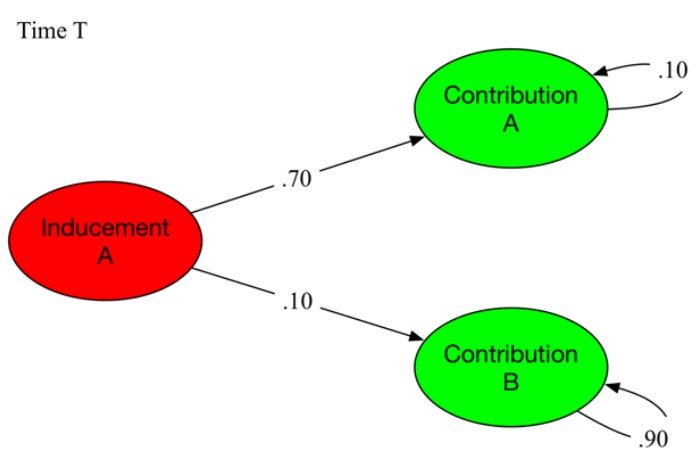

Time $\mathrm{T}+1$

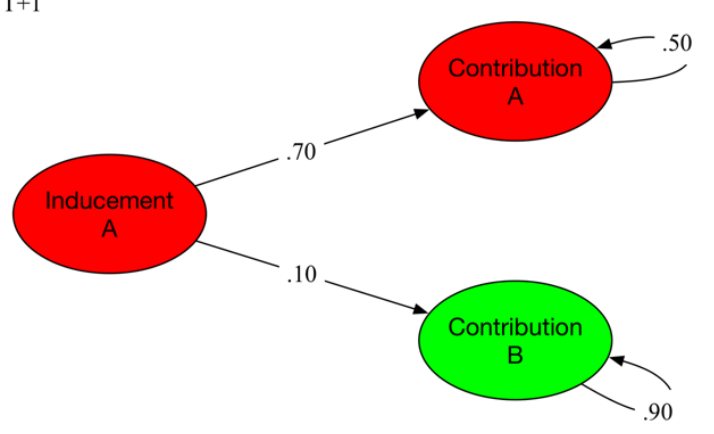

Figure 3. Impact of breached inducement on state of connected contributions at a later point in time. Green nodes represent fulfilled state, red nodes represent under-fulfilled state. Arrows between different nodes represent exchanges, with higher numbers indicating stronger exchanges. Arrows from and to the same node represent attractor strength, with higher numbers indicating that the state of the node is more resistant to change. Note that the attractor strength of contribution A changes over time, because different attractor strengths are proposed to exist for the under-fulfilment and fulfilment states. 